\title{
ANALYSIS OF THE ROLE OF THE MANINDO SIABU COOPERATIVE PARTNERS IN INCREASING THE INCOME OF COOPERATIVE MEMBERS (CASE STUDY IN SIMANINGGIR VILLAGE)
}

\author{
Anni Sofiyah ${ }^{1}$, Kamaluddin $^{2}$, Ihdi Aini ${ }^{3}$, Ali Hardana ${ }^{4}$ \\ ${ }^{1}$ IAIN Padangsidimpuan (Perbankan Syariah, FEBI, IAIN Padangsidimpuan) \\ ${ }^{2}$ IAIN Padangsidimpuan (Hukum Syariah, FEBI, IAIN Padangsidimpuan) \\ ${ }^{3}$ IAIN Padangsidimpuan (Perbankan Syariah, FEBI, IAIN Padangsidimpuan) \\ ${ }^{4}$ IAIN Padangsidimpuan (Perbankan Syariah, FEBI, IAIN Padangsidimpuan) \\ ${ }^{5}$ IAIN Padangsidimpuan (Perbankan Syariah, FEBI, IAIN Padangsidimpuan) \\ annisofiyah@gmail.com ${ }^{1}$, kamaluddin@iain-padangsidimpuan.ac.id ${ }^{2}$,ihdiaini@iain-padangsidimpuan.ac.id, ${ }^{3}$ \\ alihardana@iain-padangsidimpuan.ac.id ${ }^{4}$
}

\begin{abstract}
ABSTRAK
Koperasi Mitra Manindo Siabu merupakan tempat sasaran gerakan ekonomi masyarakat, dimana kerjasama didalamnya mewarnai nilai Islam kehidupan ekonomi masyarakat. Pendapatan masyarakat merupakan pengembangan Koperasi Mitra Manindo. Awal mula berdirinya Koperasi Mitra Mnaindo ini karena adanya keinginan untuk meningkatkan pendapatan di setiap angggota koperasi yang ikut aktif dalam operasional koperasi, namun pada 5 tahun terakhir anggota Koperasi Mitra Manindo mengalami penurunan, padahal salah satu faktor yang mempengaruhi pendapatan anggota adalah partisipasi anggota koperasi itu sendiri. Teori dalam penelitian ini berkaitan dengan teori pendapatan membahas mengenai pengertian pendapatan dan fungsi-fungsi pendapatan. Teori koperasi membahas mengenai pengertian koperasi, manajemen koperasi, landasan hukum koperasi, jenis koperasi, prinsip koperasi syariah, sumber-sumber dana koperasi, pendapatan koperasi. Teori peranan membahas mengenai peran koperasi di Indonesia peran koperasi syariah, dan peran koperasi dalam meningkatkan pendapatan. Jenis penelitian ini adalah penelitian kualitatif dengan metode-metode deskriptif yang menggambarkan bagaimana sebenarnya yang terjadi dilapangan dengan teknik pengumpulan data adalah wawancara, observasi dan dokumentasi secara langsung di Desa Simaninggir. Data yang digunakan dalam penelitian ini adalah data primer dan sekunder. Analisis data yang dilakukan pada penelitian ini kualitatif deskriptif yang dilakukan dengan wawancara langsung dengan memberikan 8 pertanyaan kepada informan yang berjumlah 20 orang. Teknik pengecekan keabsahan data yaitu: triangulasi, menggunakan bahan referensi, dan perpanjangan pengamatan. Hasil penelitian ini adalah Koperasi Mitra Manindo telah memenuhi perannya sebagai lembaga keuangan, dan telah membantu masyarakat Desa Simaninggir meningkatkan pendapatan anggota, khususnya anggota Koperasi Mitra Manindo dengan memberikan bantuan modal usaha kepada anggota koperasi, dan mengurangi ketergantungan anggota kepada koperasi berjalan guna untuk meningkatkan kesejahteraan perekonomian anggotanya.
\end{abstract}

Kata Kunci: Peranan, Koperasi Pendapatan 
ABSTRACT

Mitra Manindo Siabu Cooperative is the target place for the community's economic movement, where cooperation in it colors the Islamic values of the community's economic life. Community income is the development of Mitra Manindo Cooperative. The beginning of the establishment of the Mitra Mnaindo Cooperative was due to the desire to increase the income of each cooperative member who was actively involved in the operation of the cooperative, but in the last 5 years the members of the Mitra Manindo Cooperative have decreased, even though one of the factors that affect the income of members is the participation of the members of the cooperative itself. . The theory in this study is related to income theory, discussing the meaning of income and income functions. Cooperative theory discusses the meaning of cooperatives, cooperative management, cooperative legal basis, types of cooperatives, sharia cooperative principles, sources of cooperative funds, cooperative income. Role theory discusses the role of cooperatives in Indonesia, the role of sharia cooperatives, and the role of cooperatives in increasing income. This type of research is a qualitative research with descriptive methods that describe how what actually happened in the field with data collection techniques are interviews, observation and documentation directly in Simaninggir Village. The data used in this study are primary and secondary data. The data analysis carried out in this qualitative descriptive study was conducted by direct interviews by giving 8 questions to the informants totaling 20 people. Techniques for checking the validity of the data are: triangulation, using reference materials, and extending observations. The results of this study are the Mitra Manindo Cooperative has fulfilled its role as a financial institution, and has helped the Simaninggir Village community increase the income of members, especially members of the Mitra Manindo Cooperative by providing business capital assistance to cooperative members, and reducing the dependence of members on existing cooperatives in order to improve economic welfare. its members.

Keywords: Role, Income Cooperatives

\section{A. PENDAHULUAN}

Koperasi simpan pinjam adalah koperasi yang bergerak dalam penumpukan simpanan anggotanya untuk dipinjamkan kembali kepada anggotanya yang membutuhkan bantuan modal untuk usahanya. Selain itu, koperasi ini juga bertujuan mendidik anggotanya bersifat hemat dan gemar menabung serta menghindari anggotanya dari jeratan para rentenir. Koperasi Mitra Manindo adalah salah satu koperasi simpan pinjam yang ada di Panyabungan. Koperasi Mitra Manindo yang didirikan para tokoh perantau yang memiliki perhatian kepada kampung halaman.
Koperasi Mitra Manindo Kantor Kas Siabu, Kabupaten Mandailing Natal telah dibuka pada tanggal 1 Mei 2012, berdirinya Koperasi Mitra Manindo Kantor Kas Siabu didasari oleh besarnya minat masyarakat terhadap koperasi berbasis syariah, dimana jika dilihat dari perkembangan jumlah anggota Koperasi Mitra Manindo Kantor Kas Siabu mengalami penurunan sebagaimana dalam tabel berikut:

Tabel 1

Jumlah Anggota Koperasi Mitra Manindo Kantor Kas Siabu

\begin{tabular}{|l|l|l|}
\hline No & Tahun & Jumlah Anggota \\
\hline 1 & 2014 & 753 orang \\
\hline 2 & 2015 & 632 orang \\
\hline 3 & 2016 & 511 orang \\
\hline 4 & 2017 & 481 orang \\
\hline
\end{tabular}




\begin{tabular}{|l|l|l|}
\hline 5 & 2018 & 445 orang
\end{tabular}

Sumber: Koperasi Mitra Manindo Kantor Kas Siabu

Berdasarkan tabel di atas dapat dilihat bahwa jumlah anggota Koperasi Mitra Manindo pada tahun 2014 berjumlah 753 anggota, dan mengalami penurunan sebnayak 121 orang, maka tahun 2015 berjumlah sebanyak 632 anggota, tahun 2016 juga mengalami penurunan sebanyak 121 orang sehingga pada tahun tersebut jumlah keseluruhan anggota sebanyak 511. dan tahun 2017 anggota Koperasi Mitra Manindo Siabu juga mengalami penurunan sebanyak 30 orang sehingga pada tahun ini jumlah nasabah sebanyak 481, tahun 2018 Koperasi Mitra Manindo Siabu mengalami penurunan kembali sebanyak 36 anggota, sehingga pada tahun 2018 jumlah anggota sebanyak 445 orang.

Dilihat dari hasil wawancara yang telah dilakukan oleh peneliti kepada beberapa anggota yang melakukan pembiayaan di Koperasi Mitra Manindo Siabu, yang pertama dengan Ibu Tetti, beliau memperoleh pembiayaan dari Koperasi Mitra Manindo Siabu, setelah mendapat pembiayaan, pendapatannya meningkat sebesar $10 \%$. Hasil wawancara dengan Rahma, yang memiliki usaha warung menerima pembiayaan, menurutnya pendapatannya tidak mengalami peningkatan masih menetap seperti sebelum mendapatkan pembiayaan yang di berikan Koperasi Mitra Manindo Siabu, sedangkan ibu Asmina pendapatannya meningkat sebesar 5\%,
POINT Vol. 1, No. 1, Jul 2020 dan ibu Salma pendapatannya juga mengalami peningkatan sebesar $10 \% .1$

Sitio menyebutkan bahwa prinsipprinsip koperasi khususnya mengenai pendidikan perkoperasian yang didalamnya dijelaskan bahwa keberhasilan suatu koperasi sangat bergantung erat dengan partisipasi anggota. Teorinya Arifin Sitio sudah sejalan dengan hambatan yang dihadapi oleh koperasi yaitu kurang berpartisipasinya anggota dalam koperasi, dimana masih terdapat beberapa anggota yang belum memanfaatkan jasa-jasa yang ada di koperasi.2

Adapun beberapa faktor yang mempengaruhi peningkatan pendapatan anggota koperasi yaitu: Banyaknya jumlah nasabah, perkembangan pembiayaan, perkembangan bisnis, dan iuran kas anggota. Berdasarkan penelitian yang telah dilakukan peneliti menyimpulkan bahwa peran koperasi serba usaha (KSU) "mitra maju" dalam meningkatkan. kesejahteraan anggota di Kampung Sumber Sari Kecamatan Barong Tongkok Kabupaten Kutai Barat sudah terlaksana dengan baik.3

1 Wawancara dengan Anggota Koperasi Mitra Manindo Kantor Kas Siabu, Tanggal 01 Maret 2019

2 Sitio A. Tamban, Koperasi: Teori dan Praktek.. (Jakarta: PT. Galora Aksara Pratama 2001), hlm. 74.

${ }^{3}$ Maria Ira Susanti, "Peran Koperasi Serba Usaha (Ksu) " Mitra Maju” Dalam Meningkatkan Kesejahteraan Anggota Di Kampung Sumber Sari Kabupaten Kutai Barat" 
Berdasarkan hasil penelitian, analisis dan penyajian data tentang Peranan koperasi Annisa dalam meningkatkan kesejahteraan anggotanya dapat disimpulkan bahwa koperasi Annisa mempunyai peranan yang sangat besar terhadap kehidupan anggota secara khusus yang menjadi anggota koperasi. Disamping itu juga koperasi mempunyai peranan terhadap kehidupan pengurus dan karyawan koperasi serta masyarakat sekitar koperasi. 4 Dari fenomena-fenomena diatas maka peneliti tertarik untuk meneliti tentang "Analisis Peranan Koperasi Mitra Manindo Dalam Meningkatkan Pendapatan Anggota koperasi (Studi Kasus Di Desa Simaninggir)"

\section{B. METODE}

1. Lokasi dan Waktu Penelitian

$$
\text { Lokasi penelitian ini }
$$

bertempat di Desa Simaninggir, Kecamatan Siabu, Kabupaten Mandailing Natal. Adapun waktu penelitian dilaksanakan pada bulan April 2019 sampai Oktober 2019.।

2. Jenis Penelitian

Jenis penelitian ini adalah penelitian kualitatif dengan pendekatan deskriptif, yaitu penelitian yang bertujuan untuk menggambarkan secara tepat sifat-sifat suatu

Jurnal Ilmu Pemerintahan Volume 3, No. 2, 2015.

4Sri Hantuti Paramata, "Peran Koperasi Annisa Dalam Meningkatkan Kesejahteraan Anggota di Desa Parungi Kecamatan Boliyohuto Kabupaten Gorontalo. "Jurnal Administrasi, Volume 4, No. 2, Desember 2005.

$$
\text { 1) }
$$

individu, keadaan, gejala, dan kejadian yang terjadi saat sekarang. Penelitian deskriptif memusatkan perhatian pada masalah aktual sebagaimana adanya pada saat penelitian berlangsung. 5

Penelitian kualitatif yaitu jenis penelitian yang bermaksud untuk memahami fenomena tentang apa yang dialami oleh subjek penelitian dan melukiskan keadaan obyek atau peristiwa tanpa suatu maksud untuk mengambil kesimpulan-kesimpulan yang berlaku secara umum. 6

3. Subyek Penelitian

Adapun yang menjadi informan dalam penelitian ini adalah masyarakat Desa Simaninggir yang termasuk anggota Koperasi Mitra Manindo yang mampu memberikan informasi data yang diperlukan. Informan adalah orang yang diwawancarai, atau yang dimintai informasi oleh pewawancara.

4. Sumber Data

Sumber data merupakan data atau informasi yang menjadi bahan baku dalam penelitian. Sumber data dalam penelitian ini berwujud data primer dan data sekunder.

a. Data primer

Data primer merupakan data tangan pertama yang diproleh langsung dari tempat penelitian atau data yang dikumpulkan dari sumber-sumber asli untuk tujuan tertentu data primer biasanya diperoleh dengan survei lapangan yang menggunakan semua metode

5Juliansyah Nor, Metodologi Penelitian, (Jakarta: Kencana. 2011), hlm.34.

'Lexy J. Moleong, Metodologi Penelitian Kualitatif, (Bandung: PT. Remaja Rosdakarya, 2013), hlm. 6. 
Elna Sriwanna ${ }^{1}$, Ikhwanuddin Harahap ${ }^{2}$, Windari ${ }^{3}$, Ali Hardana ${ }^{4}$, Abdul Nasser Hasibuan ${ }^{5}$

pengumpulan data. Data primer dalam penelitian bersumber pada masyarakat di Desa Simaninggir.

b. Data sekunder

Data sekunder yaitu data pembantu yang digunakan sebagai pendukung dari primer seperti catatan-catatan koperasi yang menunjang tema penelitian, serta datadata yang bersumber dari studi kepustakaan atau internet, dan data yang telahdikumpulkan oleh pihak lain yang kumpulkan oleh pengumpul data dan dipublikasikan masyarak.at pengguna data.

5. Metode Pengumpulan Data

Untuk memperoleh data secara terperinci dan baik, maka penelitian menggunakan beberapa metode, yaitu daftar pertanyaan (kuesioner), wawancara dan dokumentasi.7

a. Observasi/ pengamatan, observasi adalah teknik pengumpulan data yang mengharuskan peneliti turun kelapangan mengamati hal-hal yang berkaitan dengan ruang, tempat pelaku, kegiatan, waktu peristiwa, tujuan dan perasaan. Dalam penelitian ini akan menggunkan alat bantu pencatat dan alat bantu mekanik (camera). Peneliti akan mencoba turun langsung kelapangan melihat dan mengamati di lapangan, dengan tujuan mendapatkan informasi untuk menyempurkan penelitian ini.

b. Wawancara (interview) adalah proses memperoleh keterangan untuk tujuan

${ }^{7}$ Asnawi Nur dan Masyhuri, Manajemen Pemasaran, (Malang: UIN Maliki Press, 2009), hIm. 162.
POINT Vol. 1, No. 1, Jul 2020

penelitian dengan cara tanya jawab, sambil bertatap muka antara si penanya atau pewancara dengan si penjawab atau informan dengan menggunakan alat yang dinamika interview guide (panduan wawancara). Dalam penelitian ini wawancara yang digunakan adalah wawancara tidak terstruktur.

c. Dokumentasi adalah mencari data mengenai hal-hal atau variabel yang berupa catatan, buku, surat kabar, majalah, notulen rapat, dan sebagainya.

6. Teknik Pengolahan Data dan Analisis Data

a. Pengolahan data

Teknik pengolahan data yang digunakan dalam penelitian ini adalah analisis data kualitatif dalam bentuk deskriptif. Penelitian ini tidak melalukan manipulasi data dan tujuan utama penelitian ini adalah menggambarkan secara sistematis fakta dan karakteristik objek atau subjek diteliti secara tetap. 8

b. Analisis data

Analisis data adalah tahapan yang kritis dalam proses penelitian bisnis dan ekonomi, tujuan utamanya adalah menyediakan informasi untuk memecahkan masalah. Setiah tahapan analisis data harus dimulai dengan tahapan pra analisis, yang mencakup klasifikasi, penyuntingan, dan

8 Sukardi, Metodologi Penelitian Pendidikan Kompetensi dan Prakteknya, (Jakarta: PT. Bumi Aksara, 2003), hlm. 157158. 
pemberian kode terhadap data. 9 Teknik analisis data yang dilakukan dalam penelitian ini adalah merupakan penelitian kualitatif dengan metode deskripsi. analisis secara kualitatif yaitu analisis data dengan mengelompokkan dan menyelidiki data yang diperoleh dari penelitian lapangan menurut kualitas dan kebenaranya kemudian dihubungkan dengan teori-teori pustakaan, sehingga diperoleh jawaban atas permasalahan yang diajukan.

Proses menganalisis data dimulai dengan:

a. Mencatat semua data yang tersedia dari berbagai sumber yaitu, dari wawancara, observasi, dan dokumen resmi.

b. Mengumpulkan dan memilah-milah data dengan membuat rangkuman yang inti dari hasil wawancara, observasi dan dokumen resmi.

C. Menyusun dalam satuan-satuan yang dikategorikan pada langkah selanjutnya.

d. Mengadakan pemeriksaan keabsahan data.

e. Membuat kesimpulan berdasarkan data yang diperoleh dari pemeriksaan keabsahan data.

7. Teknik Pengecekan Keabsahan Data

Penelitian kualitatif harus mengungkapkan kebenaran yang objektif.

9Mudrajad Kuncoro, Metode Riset Untuk Bisnis dan Ekonomi, (Jogjakarta: Erlangga, 2009), hlm. 185.
Karena itu keabsahan data dalam sebuah penelitian kualitatif sangat penting. Melalui keabsahan data kreadibilitas (kepercayaan) penelitian kualitatif dapat tercapai. Dalam penelitian ini menggunakan tiga teknik pengecekan keabsahan data yang didasarkan pada pendapat Sugiyono, antara lain:

a. Triangulasi

Menurut Sugiyono yang dimaksud triangulasi adalah "data dari berbagai sumber dengan berbagai pengecekan dari berbagai sumber dengan berbagai cara dan waktu".

Triangulasi

yang

digunakan dalam penelitian ini adalah triangulasi sumber yang digunakan untuk menguji kreadibilitas data yang diproleh melalui beberapa sumber, data tidak bisa dirata-ratakan seperti dalam penelitian kuantitatif, tetapi dideskripsikan dan dikategorikan mana pandangan yang sama, yang berbeda dan spesifik dari tiga sumber data tersebut. Tiga sumber yang dimaksud adalah hasil observasi, wawancara, dan dokumentasi.

b. Menggunakan Bahan Referansi

Menurut sugiyono yang dimaksud dengan menggunakan bahan referensi adalah "adanya pendukung untuk membuktikan data yang telah ditemukan peneliti", dan dalam penelitian ini, alat bantu data yang peneliti gunakan adalah alat handphone. 
Elna Sriwanna ${ }^{1}$, Hkwwanuddin Harahap ${ }^{2}$, Windari ${ }^{3}$, Ali Hardana ${ }^{4}$, Abdul Nasser Hasibuan ${ }^{5}$

c. Perpanjangan pengamatan

$\begin{array}{lrr}\text { Menurut Sugiyono } & \text { perpanjangan } \\ \text { pengamatan akan dapat } & \text { meningkatkan } \\ \text { kepercayaan/kredibilitas data? } & \text { Dengan }\end{array}$
perpanjangan pengamatan berarti peneliti kembali kelapangan, melakukan pengamatan wawancara lagi dengan sumber data yang pernah ditemui maupun yang baru. Dengan perpanjangan pengamatan ini berarti hubungan peneliti dengan narasumber akan semakin terbentuk rapport, semakin akrab (tidak ada jarak lagi), semakin terbuka, saling mempercayai sehingga tidak ada informasi yang di sembunyikan lagi. ${ }^{10}$

\section{HASIL DAN PEMBAHASAN}

Koperasi dalam mensejahterakan anggota, koperasi memberikan kemudahan bagi anggotanya untuk melakukan simpan pinjam di koperasi, kemudahan ini dapat terwujud dengan adanya pelayanan yang baik dari petugas koperasi dalam memberikan pelayanan kepada anggota dalam segala bidang usaha anggotanya, peran koperasi dalam usaha simpan pinjam, yaitu koperasi memberikan pinjaman kepada anggota yang kekurangan modal, dengan pembayaran pinjaman dicicil sekali seminggu, cicilan yang diberikan koperasi kepada anggota menurut wawancara rendah.

Berbagai peran yang diberikan Koperasi Mitra Manindo Siabu dalam meningkatkan pendapatan anggotanya, baik itu dalam bidang ekonomi maupun sosial. Dalam bidang ekonomi koperasi memberikan pelayanan untuk meningkatkan pendapatan anggota guna untuk mencapai kesejahteraan setiap anggota antara lain:

$10 /$ bid.,hlm. 461.
POINT Vol. 1, No. 1, Jul 2020

pertama koperasi melakukan usaha dengan berprikemanusiaaan yaitu dengan memberikan kepuasan kepada anggota koperasi dengan cara memberikan pelayanan kepada setiap lapisan masyarakat pada umumnya dan anggota pada khususnya, hal ini dilakukan untuk mengurangi ketergantungan anggota kepada lembaga yang akan membunuh usahanya, kedua koperasi ini mengurangi ketergantungan anggota kepada koperasi berjalan dengan cara memberikan tambahan modal kepada anggota yang kekurangan modal dalam mengelola, agar tujuan koperasi dapat terwujud yaitu mensejahterakan anggotanya, ketiga koperasi dalam memberikan pembiayaan kepada anggotanya dengan menawarkan pinjaman yang cicilannya cukup rendah dibanding dengan koperasi berjalan.

Peran koperasi bidang sosial pertama koperasi memberikan kemudahan kepada anggota, kemudahan yang diberikan Koperasi Mitra Manindo mulai pelayanan informasi mengenai operasional koperasi, kedua pelayanan yang baik dan jujur dalam berusaha dilakukan untuk meningkatkan kepercayaan anggota kepada koperasi, ketiga koperasi Menciptakan anggotanya untuk berusaha yang benar dengan bersikap jujur dan terbuka dalam mengelola usahanya, mengingat kejujuran adalah kunci utama berusaha, keempat koperasi melindungi hak dan kewajiban setiap anggota koperasi, koperasi memberikan hak penuh dari anggota, dan anggota memberikan hak dari koperasi juga, kelima koperasi memberikan pelatihan dan pengawasan, pelatihan ini sangat perlu dilakukan agar anggotanya dapat mempergunakan modal yang diberikan dengan sebaik-baiknya, dan pengawasan dilakukan untuk melihat sejauh mana anggota mampu dalam mengelola modal yang diberikan. 
Berbagai peran koperasi baik dalam bidang ekonomi maupun sosial hasil penelitian telah membuktikan bahwa Koperasi Mitra Manindo Siabu telah melakukan peran sebagi koperasi yang beroperasional sebagai lembaga keuangan simpan pinjam untuk meningkatkan pendapatan anggota, hal ini telah didukung oleh penelitian sebelumnya oleh Sri Hantuti Paramata tentang Peran Koperasi Annisa dalam Meningkatkan Kesejateraan Anggota di Desa Parungi Kecamatan Boliyohuto Kabupaten Gorontalo, bahwa keberadaan koperasi annisa sangat berperan dalam meningkatkan kesejahteraan anggotanya.

Peran yang diberikan koperasi tidak akan berjalan dengan baik tanpa adanya partisipasi anggota untuk melaksanakan peran dari Koperasi Mitra Manindo Siabu tersebut, karena suatu usaha tidak akan berjalan dengan baik jika hanya satu yang berkontribusi, untuk malakukan peran dari usaha yang diberikan koperasi untuk meningkatkan pendapatan diharapkan partisipasi anggota, disini pastisipasi anggota sangat diperlukan untuk mewujudkan tujuan dari koperasi yaitu kesejahteraan anggota. Sesuai dengan teori koperasi menurut Arifin Sitio yang menyebutkan bahwa keberhasilan suatu koperasi sangat bergantung erat dengan partisipasi anggotanya. Maka dari sini koperasi dan anggota harus menjalankan kerja sama dengan baik.

Berdasarkan hasil penelitian koperasi dan anggota sudah sama-sama berperan dalam meningkatkan pendapatan, pihak koperasi dan anggota melakukan kerjasama yang baik untuk meningkatkan pendapatan anggota dan pendapatan koperasi tentunya.

\section{PENUTUP}

\section{Kesimpulan}

Setelah dilakukan penelitian mengenai peranan Koperasi Mitra Manindo Dalam Meningkatkan Pendapatan Anggota Koperasi di Desa Simaninggir. Maka dapat ditarik kesimpulan bahwa Koperasi Mitra Manindo Siabu mempunyai peran yang sangat besar terhadap kehidupan angggota secara khusus dan masyarakat pada umumnya.

Koperasi Mitra Manindo Siabu melakukan peran untuk meningkatkan pendapatan anggota seperti dalam bidang ekonomi yaitu: pertama memberikan motif usaha yang berprikemanusiaan dengan memberikan pelayanan yang tidak mencari keuntungan tujuan utamanya, melainkan kesejahteraan anggota, kedua berusaha mengurangi ketergantungan anggotanya kepada yang memonopoli pasar, ketiga koperasi menawarkan jasa pinjaman dengan cicilan yang lebih rendah.

Bidang sosial koperasi yaitu: pertama, memberikan pelayanan informasi, kedua, mengembangkan pektek-praktek tata niaga yang benar dan jujur, ketiga menerapkan sikap jujur kapada anggota, keempat melindungi hak dan kewajiban anggota, kelima memberikan pelatihan dan pengawasan kepada anggotanya. Peran yang diberikan Koperasi Mitra Manindo Siabu baik dalam bidang ekomoni maupun dalam bidang sosial yang diberikan kopeasi dapat meningkatkan pendapatan anggota 
Elna Sriwanna ${ }^{1}$, Hkwwanuddin Harahap ${ }^{2}$, Windari ${ }^{3}$, Ali Hardana ${ }^{4}$, Abdul Nasser Hasibuan ${ }^{5}$

koperasi khususnya anggota yang berada di

Desa Simaninggir.

\section{Saran}

Berdasarkan kesimpulan yang ada, dalam peranan Koperasi Mitra Manindo Siabu dalam meningkatkan pendapatan anggota koperasi yang ada di Desa Simaninggir Kecamatan Siabu Kabupaten Mandailing Natal maka peneliti mengemukakan sarannya sebagai berikut:

1. Bagi petugas Koperasi Mitra Manindo Siabu disarankan untuk lebih mengembangkan usahanya, lebih mengoptimalkan peran koperasi sebagai suatu badan hukum yang mempunyai prinsip-prinsip perkoperasian sebagai jati diri badan usaha yang bergerak dalam kegiatan bisnis, dengan berasaskan kekeluargaan demi memajukan kesejahteraan anggota khususnya dan masyarakat umumnya.

2. Bagi anggota Koperasi Mitra Manindo Siabu diharapkan untuk lebih giat untuk berusaha dalam meningkatkan perekonomiannya dan memberikan pengembalian pinjaman yang telah di berikan Koperasi Mitra Manindo tepat waktu agar terjalin kerjasama yang baik untuk tujuan kesejahteraan anggota khusunya dan masyarakat umumnya.

3. Bagi peneliti lain sebagai bahan pertimbangan dan referensi dalam pengkajian penelitian selanjutnya, dan juga dapat memperluas cakupan penelitian dan jumlah unit analisis yang dapat memberikan hasil penelitian yang baik dan lebih akurat.

\section{DAFTAR PUSTAKA}

Ali Hardana, ANALISIS FAKTOR-FAKTOR YANG MEMPENGARUHI PENDAPATAN INDUSTRI KECIL DI KOTA PADANGSIDIMPUAN DAN \begin{tabular}{l} 
KABUPATEN TAPANULI SELATAN \\
Hardana \\
\hline
\end{tabular} Tazkir : Jurnal Penelitian IImu-ilmu Sosial dan Keislaman (iain-padangsidimpuan.ac.id)

Asnawi Nur dan Masyhuri, Manajemen Pemasaran, Malang: UIN Maliki Press, 2009.

Departemen Agama RI, Al-Qur'an Dan Terjemahnya, Bandung: CV Penerbit J-ART, 2004.

Eti Rocheaty dan Ratih Tresnati, Kamus Istilah Ekonomi, Jakarta: PT Bumi Aksara, 2015. Juliansyah Nor, Metodologi Penelitian, Jakarta: Kencana. 2011

K.R Subramanyam dan John J. Wild, Analisis Laporan Keuangan, Jakarta: Salemba Empat, 2010

Lexy J. Moleong, Metodologi Penelitian Kualitatif, Bandung: PT. Remaja Rosdakarya, 2013.

M.Quraisah Shihab, Tafsir Al-Misbah Jilid 3, akarta Lentera Hati, 2002.

Mudrajad Kuncoro, Metode Riset Untuk Bisnis dan Ekonomi, Jogjakarta: Erlangga, 2009.

Sitio A. Tamban, Koperasi: Teori dan Praktek.. Jakarta: PT. Galora Aksara Pratama 2001.

Sukardi, Metodologi Penelitian Pendidikan Kompetensi dan Prakteknya, Jakarta: PT. Bumi Aksara, 2003. 